\title{
Evolution of Microbial Flora during Storage of Minimally Processed Herbs
}

\author{
Giorgiana Mihaela CĂTUNESCU ${ }^{1}$, Ioan ROTAR ${ }^{1}$, Roxana VIDICAN ${ }^{1}$, Ancuța M. ROTAR ${ }^{2 *}$ and Florina \\ BUNGHEZ ${ }^{2}$ \\ 1) Faculty of Agriculture, UASMV Cluj-Napoca, Calea Mănăștur 3-5, Cluj-Napoca, Romania; \\ 2) Faculty of Food Science and Technology. UASMV Cluj-Napoca, Calea Mănăștur 3-5, Cluj-Napoca, Ro- \\ mania \\ *corresponding author: anca.rotar@usamvcluj.ro
}

Bulletin USAMV series Agriculture 71(2)/2014

Print ISSN 1843-5246; Electronic ISSN 1843-5386

DOI 10.15835/buasvmcn-agr: 10818

\begin{abstract}
Post-harvest operations, handling and storage of fresh herbs may decrease the content of bioactive compounds and increase the microbial contaminants. Minimal processing can extend shelf-life and guarantee microbiological safety.The present study tested the efficacy of minimally processing of parsley (Petroselinum crispum), dill (Anethum graveolens) and lovage (Levisticum officinale) by monitoring the microbiota during cold storage. The three herbs were minimally processed and preserved at $4^{\circ} \mathrm{C}$ for 12 days. Total plate count and total yeast and mould count were determined during storage and correlated with sensory and biochemical parameters. Parsley had the highest microbial load and lovage the lowest total yeast and mould count throughout the study. Microflora increased significantly during the 12 days of storage. We found that microbial regulations lacked for minimally processed products; thus we could not compare the results with legal limits. Total plate count, total yeast and mould count were correlated negatively with the score for texture and content of total chlorophylls, vitamin C, and total polyphenols. The microbial load was also correlated with the content of volatile aroma compounds. In conclusion, the three minimally processed herbs had a high microbial contamination that increased with storage. So, in the absence of thermal processing, only legal limitations of microflora can guarantee shelf life and food security.
\end{abstract}

Keywords: dill, lovage, parsley, total plate count, total yeast and mould count

\section{INTRODUCTION}

Herbs contain bioactive compounds that promote health but they can be heavily contaminated with microorganisms. This microflora reduces shelf-life and may lead to food-related outbreaks (Campbell et al., 2001; Elviss et al., 2009; Naimi et al., 2003; Pezzoli et al., 2008). A recent WHO/ FAO report stated that leafy vegetables - herbs included - represent a high microbiological risk for food safety because they are consumed fresh (Sessmentseries, 2008). Contamination comes from the environment (soil, water, insects), manure and unhygienic handling (Sharma et al., 1984). Thus herbs contain a variety of aerobe and anaerobe bacteria, yeasts and moulds that proliferate during storage (Aziz et al., 1998; Mandeel, 2005; Martins et al., 2001; Mckee, 1995).
This is especially true for minimally processed herbs because processing damages the tissues making the product more susceptible to decay (Lopresti and Tomkins, 1997).

Many studies have identified the microorganisms present on herbs but few have considered the evolution of microflora during storage. Data are also scarce on the relation between contamination levels and the content of bioactive compounds.

We aimed to determine the evolution of microflora on herbs during storage and to correlate the results with the sensory and bio-chemical quality. We studied this correlation for three minimally processed herbs - parsley (Petroselinum crispum), dill (Anethum graveolens) and lovage (Levisticum officinale) during 12 days of storage at $4^{\circ} \mathrm{C}$. 


\section{MATERIALS AND METHODS}

Fresh parsley (Petroselinum crispum), dill (Anethum graveolens), and lovage (Levisticum officinale) were purchased from a local market and minimally processed as previously described (Cătunescu et al., 2012a, b). Samples were stored at $4^{\circ} \mathrm{C}$ and tested for microbial contamination in the $1^{\text {st }}, 5^{\text {th }}, 8^{\text {th }}$ and $12^{\text {th }}$ day of storage.

Total plate count (TPC) was determined using SR ISO 4833:2003 procedure: $5 \mathrm{~g}$ of sample were mixed with $45 \mathrm{ml}$ of saline solution $(0.85 \%$ w/v NaCl: $\mathrm{H}_{2} \mathrm{O}$ ) for 2 min (stomacher Minimix Interscience). Four decimal dilution were made; $1 \mathrm{ml}$ of each dilution was poured and mixed in nutritive agar (Oxoid Nutrient Agar CM 0003). The plates were incubated head-down for $48 \pm 2 \mathrm{~h}$ at $37^{\circ} \mathrm{C}$. TPC was determined using equation 1 .

$$
T P C=\frac{\sum C}{M\left(n_{1}+0.1 \cdot n_{2}\right) \cdot d}
$$

TPC - total plate count

$\Sigma C$ - sum of colonies per plate

$\mathrm{Mv}$ - mass of herb sample

$\mathrm{n}_{1}$ - number of counted plates for

the $1^{\text {st }}$ dilution

$\mathrm{n}_{2}$ - number of counted plates for

the $2^{\text {nd }}$ dilution

$\mathrm{d}$ - first dilution to be counted

Total yeast and mould count (TYMC) was determined using SR ISO 21527-1:2008 procedure: $0.1 \mathrm{ml}$ of the dilutions prepared for TPC were spread on DRBC agar (Oxoid DRBC Agar CM 0003). The plates were incubated for 5 days at $25^{\circ} \mathrm{C}$. TYMC was determined using equation 2 .

$$
T Y M C=\frac{\sum C}{M\left(n_{1}+0.1 \cdot n_{2}\right) \cdot d}
$$

TYMC - total yeast and mould count

$\Sigma \mathrm{C}$ - sum of colonies per plate

$\mathrm{Mv}$ - mass of herb sample

$\mathrm{n}_{1}$ - number of counted plates for the $1^{\text {st }}$ dilution

$\mathrm{n}_{2}-$ number of counted plates for the $2^{\text {nd }}$

dilution

$\mathrm{d}$ - first dilution to be counted

The sensory attributes, chlorophylls, total polyphenols, vitamin $\mathrm{C}$ and volatile aroma compounds were previously determined (Cătunescu et al., 2012a, b).

Means, standard deviations, ANOVA ( $p$-value $<0.05$ ), Fisher (LSD, $p$-value $<0.05$ ) and Pearson coefficient were computed using XLSTAT statistical software (MS Excel, Addinsoft, New York USA, Version 2012.4.03).

\section{RESULTS AND DISCUSSION}

Parsley was the most contaminated of the three herbs with a total plate (TPC) count of $3.9 \cdot 10^{5} \mathrm{UFC} / \mathrm{g}$ (fig. 1). Some authors found a similar microbial load 5.78 log UFC/g for fresh-cut lettuce (Zhang et al., 2006) but others reported higher values: 6 - $7 \log$ UFC/g for lettuce, mint and cilantro (Trigo et al., 2006).

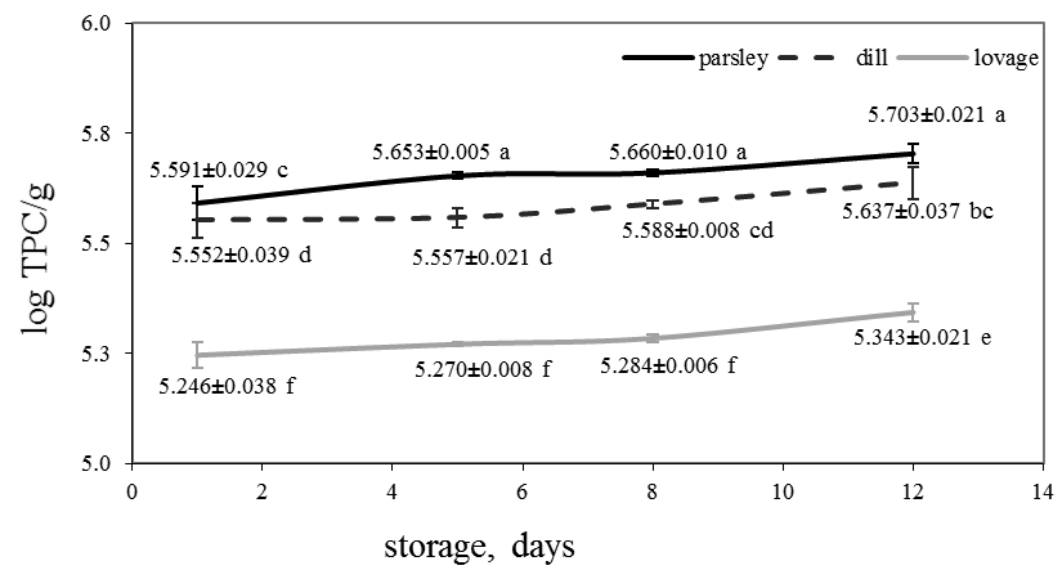

Note: Different letters represent significant statistical differences Fisher ((LSD), $p<0.05$ )

Fig. 1. Total plate count (TPC) of minimally processed parsley, dill and lovage during storage 


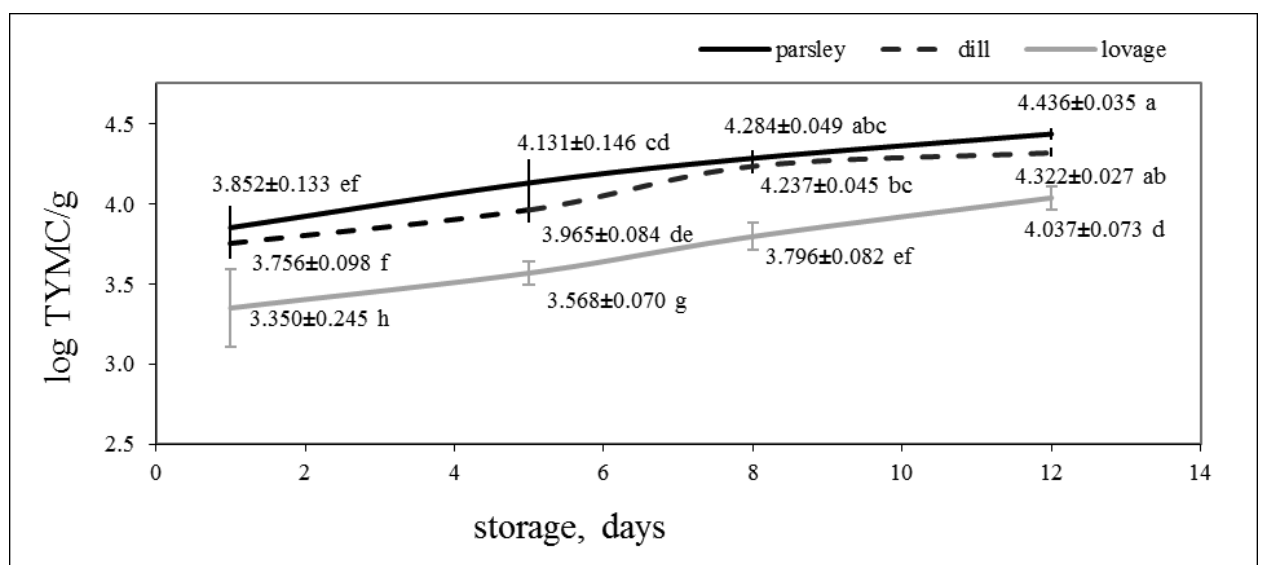

Note: Different letters represent significant statistical differences Fisher ((LSD), $p<0.05$ ).

Fig. 2. Total yeast and mould count (TYMC) of minimally processed parsley, dill and lovage during storage

The TPC increased significantly for parsley until the $5^{\text {th }}$ day of storage but remained constant for dill and lovage. The TPC of the two began to increase after this stage. At the end of trials the growth was of $30 \%$ for parsley, $22 \%$ for dill, and $25 \%$ for lovage. TPC was correlated strongly positively with storage $\left(r_{\text {(parsley) }}=0.97 ; r_{\text {(dill) }}=0.94\right.$; $\left.r_{\text {(lovage) }}=0.96 ; p<0.05\right)$. Basbayraktar et al. (2006) and Lu et al. (2005) found increases below 1 log for minimally processed salad mixes stored at $5^{\circ} \mathrm{C}$ for 10 days and for minimally processed celery leaves stored at $4^{\circ} \mathrm{C}$ for 9 days. Trigo et al. (2006) determined much higher levels - up to $8 \log \mathrm{UFC} / \mathrm{g}$ - for parsley stored at $4^{\circ} \mathrm{C}$ for 25 days.

Romania and Europe seem to lack regulations for the TPC and TYMC of minimally processed foods. Romanian standard - STAS 12550/87 stated the quality of leafy vegetables and specified only sensory parameters with no microbial limits. The President of The National Authority for Sanitary and Veterinary Safety of Food (ANSVSA) gave the Order no. 27 in 6 June 2011 that specified microbiological restrictions for frozen vegetables but neglected fresh leafy vegetables (herbs included) and minimally processed products. The Regulation of European Commission (EC) No. $2073 / 2005$ provides microbiological criteria for pre-cut fruit and vegetables (ready-to-eat) but limits only pathogens: Salmonella an E. coli.

Mohacsi-Farkas et al. (2006) suggest a target TPC of $10^{6} \mathrm{UFC} / \mathrm{g}$ and a tolerated TPC of $10^{7} \mathrm{UFC} / \mathrm{g}$ for the production day. A maximum TPC of $10^{8}$ UFC/g indicated the end of shelf-life. We concluded that the three herbs had a microbial load below the target TPC until the $12^{\text {th }}$ day of storage which indicates a low initial contamination.

The TYMC of three herbs exceeded $10^{3} \mathrm{UFC} / \mathrm{g}$ - the target proposed by Mohacsi-Farkas et al. (2006) - and approached the tolerated $10^{4} \mathrm{UFC} / \mathrm{g}$ (Fig. 2). Parsley had the highest contamination. Lu et al. (2005) and Hammad et al. (2006) found similar values for celery leaves (3.54 log UFC/g), lettuce $\left(1.2 \cdot 10^{4} \mathrm{UFC} / \mathrm{g}\right)$, and salad mixes $\left(1.1 \cdot 10^{4}\right.$ UFC/g). Basbayraktar et al. (2006) reported higher loads of yeasts and moulds for salad mixes (6.32 log UFC/g).

TYMC increased significantly during storage: by $0.58 \log \mathrm{UFC} / \mathrm{g}$ in parsley, $0.57 \mathrm{log} \mathrm{UFC} / \mathrm{g}$ in dill, and $0.69 \log$ UFC/g in lovage. Parsley and dill had a similar load, while lovage had a significantly lower contamination level. TYMC was correlated strongly positively with storage $\left(r_{\text {parsley }}=0.99\right.$; $r_{\text {dill }}=0.97 ; r_{\text {lovage }}=1.00 ; p<0.05$ ).

Similarly, Basbayraktar et al. (2006) observed an increase of 0.41 to $0.51 \log \mathrm{UFC} / \mathrm{g}$ for salad mixes stored for 7 days at $5^{\circ} \mathrm{C}$. Hammad et al. (2006) determined, however, increased TYMC: $1.14 \log \mathrm{UFC} / \mathrm{g}$ for lettuce and $1.53 \mathrm{log} \mathrm{UFC} / \mathrm{g}$ for green beans, both minimally processed and stored at refrigeration temperatures for 7 and 10 days, respectively. This suggested that TYMC increases dependent to the initial load and the product tested.

TYMC varied proportionally to TPC: $r_{\text {parsley }}=$ $0.98, r_{\text {dill }}=0.98$, and $r_{\text {lovage }}=0.88(p<0.05)$.

Pearson correlation coefficient was used to determine the influence of TPC and TYMC on the sensory and bio-chemical quality of the three herbs. 
The microbial load of dill and lovage was correlated negatively with texture (tab. 1). Their tissues softened when reaching the end of shelf-life - 14 days for dill and 15 days for lovage (Cătunescu et al., 2012a). The decrease of firmness was caused by the physiological and microbial degradation of cellulose while the decrease of succulence was attributed to water loss through respiration.

Parsley showed no significant correlations between the microbiota and texture (tab. 1). It had the highest contamination level but the longest shelf-life, so its sensory quality changed least of the three herbs although.

The content of chlorophylls and vitamin $\mathrm{C}$ was correlated strongly with microbial load (tab. 2). These compounds oxidise with storage (Cătunescu et al., 2012b) while contamination flora increases exponentially. Research shows, however, that chlorophylls have antimicrobial and antifungal activity that might explain this inverse relation (Kakkar, 2012; Maekawa et al., 2007; Mowbray,
1957). Similar, vitamin C controls directly and indirectly the microbiota (Kallio et al., 2012)

Several studies indicate polyphenols being responsible for the antimicrobial activity of plants (Tajkarimi et al., 2010). In the present study, however, the content of total phenols did not correlate with microbial load (tab. 2). Thus, the content must be higher for polyphenols to control the contamination level.

The content and type of volatile aroma compounds affected the TPC and TYMC but the strength and direction of the correlation varied among the three herbs (tab. 3). The content of $\alpha$-phellandrene was correlated strongly positively with the TYMC of dill but negatively for lovage. Its antibacterial activity was confirmed for plants form Artemisia and Vetiveria families (Duke, 2014). The content of $\beta$-myrcene and $\beta$ - phellandrene was correlated negatively with the TYMC of dill. Both compounds have strong antifungal activity (Duke, 2014).

Tab. 1. Correlation of sensory texture with total plate count (TPC) and total yeast and mould count (TYMC) of minimally processed parsley, dill and lovage

\begin{tabular}{|c|c|c|c|c|c|c|}
\hline Attribute & \multicolumn{6}{|c|}{ Pearson correlation coefficient $(r)$} \\
\hline & \multicolumn{2}{|c|}{ parsley } & \multicolumn{2}{|c|}{ dill } & \multicolumn{2}{|c|}{ lovage } \\
\hline TPC & & TYMC & TPC & TYMC & TPC & TYMC \\
\hline Firmness & -0.19 & -0.35 & -0.99 & -0.95 & -0.97 & -0.90 \\
\hline Succulence & -0.59 & -0.70 & -0.88 & -1.00 & -0.90 & -0.97 \\
\hline Texture & -0.42 & -0.56 & -0.91 & -1.00 & -0.94 & -0.99 \\
\hline
\end{tabular}

Note: Values in bold are different from 0 with a significance level $\alpha=5 \%$

Tab. 2. Correlation of chlorophylls, total phenols and vitamin C content with total plate count (TPC) and total yeast and mould count (TYMC) of minimally processed parsley, dill and lovage

\begin{tabular}{lcccccc}
\hline \multirow{2}{*}{ Bioactive compounds } & \multicolumn{4}{c}{ Pearson correlation coefficient $(r)$} \\
\cline { 2 - 7 } & \multicolumn{2}{c}{ parsley } & \multicolumn{3}{c}{ dill } & \multicolumn{3}{c}{ lovage } \\
\cline { 2 - 7 } & TPC & TYMC & TPC & TPC & TYMC & TPC \\
\hline Chlorophyll a & -0.72 & -0.63 & -0.92 & -0.66 & -0.82 & -0.63 \\
\hline Chlorophyll b & -0.86 & -0.94 & $\mathbf{- 1 . 0 0}$ & -0.89 & -0.60 & -0.79 \\
\hline Total chlorophylls & -0.87 & -0.82 & $\mathbf{- 0 . 9 5}$ & -0.73 & -0.95 & -0.83 \\
\hline Total phenols & -0.43 & -0.40 & -0.35 & 0.12 & -0.60 & -0.57 \\
\hline Vitamin C & $\mathbf{- 0 . 9 8}$ & $\mathbf{- 0 . 9 9}$ & -0.92 & $\mathbf{- 0 . 9 8}$ & -0.99 & -0.97 \\
\hline
\end{tabular}

Note: Values in bold are different from 0 with a significance level $\alpha=5 \%$ 
Tab. 3. Correlation of volatile aroma compounds content with total plate count (TPC) and total yeast and mould count (TYMC) of minimally processed parsley, dill and lovage

\begin{tabular}{|c|c|c|c|c|c|c|}
\hline \multirow{3}{*}{ Bioactive compounds } & \multicolumn{6}{|c|}{ Pearson correlation coefficient $(r)$} \\
\hline & \multicolumn{2}{|c|}{ parsley } & \multicolumn{2}{|c|}{ dill } & \multicolumn{2}{|c|}{ lovage } \\
\hline & TPC & TYMC & TPC & TPC & TYMC & TPC \\
\hline 1.3.8-p-menthatriene & 0.02 & -0.07 & - & - & - & - \\
\hline 2-methyl-1-propenyl-benzene & -0.24 & -0.36 & - & - & - & - \\
\hline$\alpha$-phellandrene & 0.18 & 0.28 & 0.80 & 0.95 & -0.80 & -0.82 \\
\hline$\alpha$-pinene & 0.57 & 0.42 & -0.82 & -0.60 & -0.44 & -0.19 \\
\hline$\alpha$-terpinolene & - & - & - & - & -0.70 & -0.68 \\
\hline$\beta$-phellandrene & 0.28 & 0.43 & -0.81 & -0.98 & 0.40 & 0.39 \\
\hline$\beta$-myrcene & -0.53 & -0.50 & -0.89 & -0.99 & 0.92 & 0.80 \\
\hline$\beta$-pinene & 0.17 & -0.03 & -0.88 & -0.64 & -0.41 & -0.16 \\
\hline$\beta$-trans-ocymene & - & - & -0.62 & -0.88 & - & - \\
\hline d-limonene & 0.25 & 0.13 & -0.74 & -0.89 & -0.91 & -0.80 \\
\hline$\gamma$-terpinene & -0.78 & -0.83 & - & - & - & - \\
\hline o-cymene & -0.49 & -0.51 & -0.47 & -0.81 & 1.00 & 0.95 \\
\hline camphen & - & - & - & - & -0.35 & -0.11 \\
\hline dehydro- $\rho$-cimene & -0.77 & -0.82 & - & - & & \\
\hline sabinene & - & - & - & - & -0.83 & -0.65 \\
\hline terpinolene & 0.11 & -0.00 & -0.95 & -0.90 & - & - \\
\hline
\end{tabular}

Note: Values in bold are different from 0 with a significance level $\alpha=5 \%$

\section{CONCLUSION}

The three minimally processed herbs had a high initial contamination but below the TPC limit established by current research. This suggests the use of fresh herbs of high quality and good processing conditions. The herbs were heavily contaminated with yeasts and moulds and had a TYMC close to the tolerated limit of $10^{4} \mathrm{UFC} / \mathrm{g}$. Parsley was the most contaminated and lovage the least contaminated. The ranking was maintained until the $12^{\text {th }}$ day of storage when the TPC and TYMC increased significantly for all three herbs.

The contamination microbiota was correlated with the texture, content of chlorophylls, vitamin $\mathrm{C}$ and volatile aroma compounds. The content of chlorophylls, vitamin $\mathrm{C}, \quad \beta$-myrcene, and $\beta$-phellandrene influenced negatively the TPC and TYMC of the three herbs.

We found a lack of European policy regarding the microbial criteria of minimally processed products. Only a strict limitation of TPC and TYMC can guarantee the shelf-life and food security of the products in the absence of thermal processing.

\section{Acknowledgments}

This paper was published under the frame of European Social Fund, Human Resources Development Operational Programme 2007-2013, project no. POSDRU/159/1.5/S/132765.

\section{REFERENCES}

1. Aziz NH, Youssef YA, El-Fouly MZ, Moussa LA (1998). Contamination of some common medicinal plant samples and spices by fungi and their mycotoxins. Botanical Bulletin of Academia Sinica 39.

2. Basbayraktar V, Halkman H, Yucel P, Cetinkaya N (2006). Use of irradiation to improve the safety and quality of minimally processed fruits and vegetables. Use of Irradiation to Ensure the Hygienic Quality of Fresh, PreCut Fruits and Vegetables and Other Minimally Processed Food of Plant Origin:243.

3. Campbell JV, Mohle-Boetani J, Reporter R, Abbott S, Farrar J, Brandl M, Mandrell R, Werner SB (2001). An outbreak 
of Salmonella serotype Thompson associated with fresh cilantro. Journal of Infectious Diseases 183:984-987.

4. Cătunescu GM, Tofană M, Mureșan C, David A, Stănilă S (2012a). Sensory Evaluation of Minimally Processed Parsley (Petroselinum crispum), Dill (Anethum graveolens) and Lovage (Levisticum officinale) Stored at Refrigeration Temperatures. Bulletin of University of Agricultural Sciences and Veterinary Medicine Cluj-Napoca Agriculture 69.

5. Cătunescu GM, Tofană M, Mureșan C, Ranga F, David A, Muntean M (2012b). The effect of cold storage on some quality characteristics of minimally processed parsley (Petroselinum crispum), dill (Anethum graveolens) and lovage (Levisticum officinale). Bulletin of University of Agricultural Sciences and Veterinary Medicine ClujNapoca Agriculture 69.

6. Duke J (2014). Dr. Duke's phytochemical and ethnobotanical databases, phytochemical database. USDAARS-NGRL, Beltsville Agricultural Research Centre, Maryland, USA

7. Elviss N, Little C, Hucklesby L, Sagoo S, Surman-Lee S, De Pinna E, Threlfall E (2009). Microbiological study of fresh herbs from retail premises uncovers an international outbreak of salmonellosis. International journal of food microbiology 134:83-88.

8. Hammad A, Abo Elnour S, Salah A (2006). Use of irradiation to ensure hygienic quality of minimally processed vegetables and fruits.

9. Kakkar A (2012). Microwave assisted isolation and evaluation of chlorophyll from wheatgrass and study on its antimicrobial activity. IJPRD 4: 8, 142145.

10. Kallio J, Jaakkola M, Mäki M, Kilpeläinen P, Virtanen V (2012). Vitamin C Inhibits Staphylococcus aureus Growth and Enhances the Inhibitory Effect of Quercetin on Growth of Escherichia coli In Vitro. Planta medica 78:1824-1830.

11. Lopresti J, Tomkins B (1997). Postharvest handling and packaging of fresh herbs. Institute for Horticultural Development Agriculture Victoria RIRDC 97.

12. Lu Z, Yu Z, Gao X, Lu F, Zhang L (2005). Preservation effects of gamma irradiation on fresh-cut celery. Journal of Food Engineering 67:347-351.

13. Maekawa LE, Lamping R, Marcacci S, Maekawa MY, Nassri MRG, Koga-Ito CY (2007). Antimicrobial activity of chlorophyll-based solution on Candida albicans and Enterococcus faecalis. RSBO (Impr) 4

14. Mandeel QA (2005). Fungal contamination of some imported spices. Mycopathologia 159:291-298.

15. Martins HnM, Martins MLg, Dias MI, Bernardo F (2001). Evaluation of microbiological quality of medicinal plants used in natural infusions. International journal of food microbiology 68:149-153.
16. McKee L (1995). Microbial contamination of spices and herbs: a review. LWT-Food Science and Technology 28:111.

17. Mohacsi-Farkas C, Farkas J, Andrassy E, Polyak-Feher K, Brückner A, Kisko G, Agoston R (2006). Improving the microbiological safety of some fresh pre-cut and prepackaged chilled produce by low-dose gamma irradiation. Use of Irradiation to Ensure the Hygienic Quality of Fresh, Pre-Cut Fruits and Vegetables and Other Minimally Processed Food of Plant Origin:130.

18. Mowbray S (1957). The antibacterial activity of chlorophyll. British medical journal 1:268.

19. Naimi TS, Wicklund JH, Olsen SJ, Krause G, Wells JG, Bartkus JM, Boxrud DJ, Sullivan M, Kassenborg H, Besser JM (2003). Concurrent outbreaks of Shigella sonnei and enterotoxigenic Escherichia coli infections associated with parsley: implications for surveillance and control of foodborne illness. Journal of Food Protection 66:535-541.

20. Pezzoli L, Elson R, Little CL, Yip H, Fisher I, Yishai R, Anis E, Valinsky L, Biggerstaff M, Patel N (2008). Packed with Salmonella-investigation of an international outbreak of Salmonella Senftenberg infection linked to contamination of prepacked basil in 2007. Foodborne pathogens and disease 5:661-668.

21. SESSMENTSERIES M (2008). Microbiological hazards in fresh fruits and vegetables

22. Sharma A, Ghanekar A, Padwal-Desai S, Nadkarni G (1984). Microbiological status and antifungal properties of irradiated spices. Journal of agricultural and food chemistry 32:1061-1063.

23. Tajkarimi M, Ibrahim S, Cliver D (2010). Antimicrobial herb and spice compounds in food. Food Control 21:11991218.

24. Trigo M, Ferreira A, Sapata M, Sousa M, Curado T, Andrada L, Erreira E, Botelho M, Veloso M (2006). Improving quality and safety of minimally processed fruits and vegetables by gamma irradiation. Use of Irradiation to Ensure the Hygienic Quality of Fresh, Pre-Cut Fruits and Vegetables and Other Minimally Processed Food of Plant Origin:225.

25. Zhang L, Lu Z, Lu F, Bie X (2006). Effect of $\gamma$ irradiation on quality-maintaining of fresh-cut lettuce. Food Control 17:225-228.

26. SR ISO 4833:2003 Microbiology of the food chain - Horizontal method for the enumeration of microorganisms

27. SR ISO 21527-1:2008 Microbiology of food and animal feeding stuffs - Horizontal method for the enumeration of yeasts and moulds.

28. STAS 12550-87 Verdețuri. Frunzoase. 